\title{
The Application of the Symbol of Oroqen National Arts and Crafts in Art Design
}

\author{
Li Siyuan, Huang Jian \\ Heihe University, Heihe, Heilongjiang 164300
}

Keywords: Oroqen nationality; Arts and Crafts; Symbolization; Application

\begin{abstract}
Oroqen minority is an ancient ethnic group with a long history in China. Because of the unique texture of birch bark, it has been widely used by the Oroqen people during the period of the clans. The Oroqen people live an uncertain life of migration with the constant changes of wild animals and hunting grounds. Birch Bark products are light and strong, not afraid of falling, wear-resisting, durable and easy to dismantle. They are most suitable for hunting lifestyle. A horse can be carried away by the whole family. Birch bark culture permeates every field of Oroqen people's social life. Everything that people come into contact with is included in the design of birch bark products. Therefore, it is the most true reflection of Oroqen's production and life, and it is the ancient traditional culture and art of ethnic minorities in China.
\end{abstract}

\section{Introduction}

The Oroqen nationality is one of the least populous ethnic minorities in China, and its main habitation is Inner Mongolia and Heilongjiang Province. From an early age, he heard "a tall forest in the Xingan ridge and a brave Oroqen in the forest. A horse, a horse, a gun, a mountain forest. " It is the lush forest sea hovering around the Xing'an Mountains of all sizes that breeds the unique birch bark culture of the Oroqen ethnic minorities. Birch Bark products are light and durable, beautiful, rich in sources, easy to carry and so on. They cater to the unique hunting lifestyle and natural environment of the Oroqen people, and become the representative national arts and crafts of the Oroqen people. Up to now, the development of modern science and technology has brought great changes to the production and life of this hunting nation. Birch bark culture is quietly fading out of the life of the Oroqen minority and our view. The so-called "national is the world". If the Chinese nation wants to establish its position in the world, besides learning advanced science, technology and cultural concepts from the western countries, the more important thing is to make sure of the gradual progress of the Chinese native culture without losing the "root" of the Chinese nation, and to extract and develop the essence of its own traditional culture. Only in this way can we synchronize with the development of the world and maintain our national character. China must maintain its national characteristics when it comes to the world. 


\section{Origin of Oroqen Birch Bark Handicraft}

According to archaeological excavation data, the history and culture of birch bark can be traced back to the late Paleolithic archaeology, and the birch bark culture gradually matured from modern times. Betula platyphylla is a deciduous tree with strong vitality. It grows in cold and temperate regions. It is tall and handsome in shape. Because of its white bark, it is called Betula platyphylla. Birch, with its straight trunk and graceful posture, adorns the size of Xingan mountain, the home of the Oroqen nationality. Birch accounts for about 20\% of all trees in Xingan ridge. The white birch trees not only decorate the earth, but also quietly bring benefits to the Oroqen people and enrich their lives. The birch bark has great effect and wide application. There are many records about the birch bark technology in the literature. In LongshaJilue Property, it was once recorded that "the best birch in Oroqen, crowns and feet, utensils, luxury tents and Zhoudu are all made of the birch bark." The eighth volume of Heilongjiang Wai Ji also mentions that there are many birches in the valley, and the leather truck is covered, curved, and Zaha. Longitudinal seam, such as Castanopsisfargesii, Dali water, small Sheng rice noodles, called the birch skin bucket. Nowadays, there are still some women in Oroqen who can make birch products, but nowadays they are far less skilled than before. In the old days, every woman in Oroqen could make birch products. Folk artists. According to the survey data of ethnology, birch bark has a very close relationship with the life of the Oroqen people. Birch Bark products are found everywhere in daily life. It can be said that birch bark products can not be separated from food, clothing, shelter, transportation, production and religious activities. For example, the birch-skin bowl and drinking-water birch-skin cup are used in the diet, the birch-skin cap and shoes are used in the clothing, the birch-bark enclosure is used in the house, and the "Olen" (barn) is also covered with the birch-skin, the birch-skin boat in the water is also wrapped in the birch-skin, the hunting tool, the birch whistle and the knife sheath are made of the birch bark outside the cradle for the baby. The noodles are also covered with birch bark. Birch Bark products are an important part of the material culture of the Oroqen nationality. They have different shapes, unique features and infinite charm, showing the unique regional cultural characteristics of the forest nationality.

\section{The Symbol of Oroqen National Arts in the Development of Modern Technology}

\subsection{Artwork}

Chinese lacquer art works form their special forms of expression, artistic charm and aesthetic characteristics with unpredictable technological means, charming national materials and unique artistic image. Because all artistic expression must have a "carrier", this carrier is material. Art depends on the material world, and the variety of art comes from the variety of material. The artistic conception of lacquer is to pay attention to the wide integration of national materials and traditional techniques, to integrate the materials used with the creator's psychological feelings, and to form a high value and modern consciousness of lacquer works. Traditional Birch Bark products and lacquer art originated from their use value, but in the era of rapid economic development, people through new artistic means to enable it to have a high artistic value. The first step in the application and development of birch bark in lacquer artworks in the arts and crafts of Oroqen ethnic minorities is to re-understand the inherent national spirit and aesthetic feeling of birch bark materials and create modern artworks with rich connotations. With the rapid development of science and technology, the art production process and techniques, materials are more rich and diverse, so that the ancient traditional art has more compatible spirit. The selection of birch bark in the arts and crafts of the Oroqen ethnic minorities, so that the style and techniques of art works have been innovated. Betula bark is not only the representation language of lacquer art, but also the cultural 
collision between the traditional national cultural connotation of its material and lacquer art has been paid more and more attention. Birch bark is both a carrier and an innovative work of art, and its functional properties have undergone important changes. Modern lacquer art reproduction forms are becoming more and more diverse. It is very important to grasp the spirit of material connotation and pay attention to the use of material language in the creation. So the creators use birch bark to conceive lacquer art works from the angle of birch bark materials, to show the beauty of material quality of art works, to use the beauty of material quality, to integrate art imagination. It is integrated with materials to provide a sense of life and a sense of strength for the viewer.

\subsection{Crafts}

\subsubsection{Tourism Souvenir Products}

The market needs tourist souvenirs with both economic and cultural connotations, which broadens the road for the development of birch bark and lacquer art souvenir market and the application of lacquer art, and becomes a good way for the sustainable development of Chinese traditional national culture and lacquer art. The integration of culture and history is the vitality of tourist souvenirs. The deep development of tourist souvenirs can start with the cultural value contained in them. Birch bark and lacquer art have a long history in our country and Chinese culture. The form of tourist souvenirs presents the human history and traditional art and culture of lacquer art in the minority areas of Oroqen, and extends the inherent cultural value of tourist souvenirs. With the development of social economy and the enthusiasm of the people to develop tourism, painted birch bark souvenirs can show the world the style and features of Oroqen, and promote the development of regional economy and culture. The development of tourist souvenirs with regional cultural characteristics combined with lacquer art can form souvenirs with national local characteristics and traditional art and culture, and expand new market points. The combination of new birch bark materials and lacquer art provides a new idea for the development of tourism products. It can provide more processing methods for Birch Bark products and enhance the expression of birch bark. The development and production of birch bark lacquer art products in tourist souvenirs, make it a collection of artistic accomplishment, visual perception, product functions, as one of the crafts, so that birch bark and lacquer art in the most natural form into people's daily life, showing the charm of modern interpretation of traditional art.

\subsubsection{Household Products}

"In the most prosperous Ming and Qing Dynasties, lacquer art has been applied to household design, in addition to a variety of utensils, such as boxes, bowls, bottles, caskets, etc., but also furniture, such as screens, wardrobes, desks, especially the Ming Dynasty lacquer furniture in the current collection area is much sought after;" Birch bark is also a minority of traditional Oroqen. It is widely used in the production and life of the nation. The application of birch bark in lacquer art is embodied in lacquer furniture, including the composition of material life and the achievement of economic and cultural development. On the premise of adapting to the modern society, the birch bark lacquer art in the design of modern lacquer furniture can be combined with modern technology means and design concepts to develop a set of modern lacquer art style and ethnic minority traditional craft and cultural characteristics of a modern cultural product. With the continuous exploration and innovation of lacquer art, the integration of new techniques and design concepts into modern lacquer furniture design will be closer to the fashion taste of modern home design. Combining birch bark lacquer art with modern furniture is one of the ways to inherit and apply the traditional lacquer art. Combining the characteristics of modern furniture design and production, 
using modern furniture design ideas and product production technology, the birch bark lacquer art expression effect is presented in modern furniture, and the essence of traditional culture is in the modern furniture. Carry forward and create in modern technology production.

\section{The Conformity of Oroqen National Arts and crafts}

\subsection{The Protection Consciousness of Birch Bark Gandicraft is Weak}

The birch bark art in Oroqen arts and crafts is not only a material culture, but also a manifestation of intangible culture. Birch Bark handicraft has obvious form and content from birch bark to finished handicraft and art works, but birch bark handicraft production methods, processes, and even design ideas exist in non-material form, but not actively protected. According to the investigation, there is no video recording of the traditional birch bark making technique in Oroqen. This shows that the Oroqen nationality still lacks the protection consciousness of birch bark culture in traditional culture. The social change, undeniably makes the arts and crafts industry encounter a certain destructive impact on the technical level, and the mechanical process gradually replaces the traditional handicraft. If we do not pay attention to the protection of Olunchun birch bark handicraft, the traditional arts and crafts will eventually lead to the disappearance of birch bark culture.Therefore, the loss of Arts and crafts, no successor and traditional arts, arts and crafts artists protection is not strong, such as the Oroqen crafts and crafts of birch bark technology in the status quo.

\subsection{The Birch Bark Products Brought about by the Economic Industry}

"Cultural Degradation" of the Birch Bark Culture of the Oroqen Nationality is driven by the economy and culture of Arts and crafts, making it often roam between economic and cultural industries. When Birch Bark products enter the consumer market as commodities, the art of birch bark derives this level of consumer nature. It can be said that its utilitarian intentions destroy the basic nature of art focusing on process and form. With the vigorous development of tourism, the production methods of Birch Bark products can not be as elaborate as before, driven by commercial interests. Consumer Birch Bark products are stimulated by external factors, the audience's evaluation and reflection, commercial profits and other undoubtedly caused some negative effects. Apart from the destruction of the simple style of birch bark craftsmanship of the Oroqen ethnic group, besides the damage caused by commercial factors to the artistic quality of the minority arts and crafts (as in many places nowadays, because of the stimulation and competition of the market, mass production, rough production, has long lost the natural growth and nature of the National Arts and crafts) The elaborate stage of production. Fresh aesthetic pleasure loss and so on, these social trends are likely to reduce the Oroqen birch bark culture.

\section{Conclusion}

The birch bark and lacquer art of the Oroqen ethnic minorities belong not only to the traditional arts and crafts of our country, but also to the intangible cultural heritage of our country. How to inherit and develop the traditional culture is the main significance of this thesis. A comprehensive view of the various categories of traditional arts of all ethnic groups in China, whether it is language art, plastic art or comprehensive art, has a number of "basic forms". As far as the traditional arts and crafts are concerned, when these basic forms are laid down, the traditional national art is essentially

a display of the basic forms. People can not absolutely repeat them when they are displayed. In addition, the psychological tendency of seeking perfection and increasing connotation will 
inevitably lead to the deviation of the basic forms. This deviation is a historical process, which can not be stopped, and this deviation will cause people to feel, vision and give people a new stimulus, and this new stimulus not only reappears, but also increases the traditional arts and crafts derived from the traditional aesthetic appeal.

\section{Acknowledgment}

Foundation projects: This paper is one of the achievements of the 2018 Heilongjiang Provice Art Science Planning Project "Symbolization of Northern Oroqen Ethnic Arts and Crafts in Art Sesign" (Project No.2018D053)

\section{References}

[1] Yan Qi Xiang. The memory of Chinese ethnic minorities. The rural reading press, 2001:154 to 168

[2]Yu Xue bin. Hunting life in Oroqen. Heilongjiang Fine Arts Publishing House, 2003:110 to 116

[3] Liu Yuliang. Patterns and plastic arts of hunting ethnic groups in northern China. Heilongjiang Education Publishing House, 2008:51-70

[4] Song Zhaolin, the last hunter. Shandong pictorial press, 2000:284 to 287

[5] Xiao Yun. An overview of the customs of the Oroqen nationality. Heilongjiang Institute of nationalities, 1993:138 